East African Medical Journal Vol. 87 No. 2 February 2010

MODIFIABLE FACTORS ASSOCIATED WITH ACTIVE PULMONARY TUBERCULOSIS IN A KENYAN PRISON

A. S. Amwayi, MBChB, MSc., Ministry of Public Health and Sanitation, Department of Disease Prevention and Control, Field Epidemiology and Laboratory Management Training Program (FELTP-Kenya), P.O. Box 225-00202, Nairobi, Kenya, G. M. Kikuvi, BVM, MSc, PhD., Institute of Tropical Medicine and Infectious Diseases (ITROMID), Jomo Kenyatta University of Agriculture and Technology, P.O. Box 62000- 0200, Nairobi, Kenya and E. M. Muchiri, MSc, PhD., Division of Communicable and Vector-Borne Diseases, Ministry of Health, P.O. Box 20750, Nairobi, Kenya

Request for reprints to: Dr. A. S. Amwayi, P.O. Box 225-00202, Nairobi, Kenya

\title{
MODIFIABLE FACTORS ASSOCIATED WITH ACTIVE PULMONARY TUBERCULOSIS IN A KENYAN PRISON
}

\author{
A. S. AMWAYI, G. M. KIKUVI and E. M. MUCHIRI
}

\begin{abstract}
Objectives: To establish modifiable factors associated with active pulmonary tuberculosis (PTB) among prisoners.

Design: Retrospective matched case-control study.

Setting: Nakuru GK prison in Kenya.

Subjects: A total of 144 subjects ( 48 cases and 96 controls) were recruited into the study. Cases were adult prisoners who had at least two initial sputum specimens being Acid Fast Bacilli-positive (AFB+) on direct smear microscopy and hence recruited to PTB WHO DOTS Programme. Controls were adults with no chronic cough and not on PTB treatment six months prior to the study.

Results: Independent factors significantly associated with active PTB disease were: self reported $\mathrm{HIV}+$ status $(\mathrm{OR}=11 ; 95 \% \mathrm{CI}=2.42-47.77)$, evidence of $\mathrm{BCG}$ vaccination $(\mathrm{OR}=0.20 ; 95 \% \mathrm{CI}=0.05-0.60)$, contact with $\mathrm{PTB}$ case $(\mathrm{OR}=7.0 ; 95 \% \mathrm{CI}=1.17-38.23)$, unemployment $(\mathrm{OR}=9.0 ; 95 \% \mathrm{CI}=1.84-43.97)$ and sharing linen $(\mathrm{OR}=4.32$; $95 \% \mathrm{CI}$ =1.08-17.29).

Conclusions: Modifiable factors associated with active PTB in Nakuru G.K prison are: HIV status, BCG vaccination, PTB case contact, poverty and poor personal hygiene. We recommend HIV counselling and testing of all PTB patients, screening for TB upon prison entry and TB contact investigation and improving personal hygiene of prisoners.
\end{abstract}

\section{INTRODUCTION}

World Health Organisation stated in 2005 that "prisons act as a reservoir for $\mathrm{TB}$, pumping the disease into the civilian community through staff, visitors and inadequately treated released inmates" (1). Correctional population have a much higher TB case rates than the general population due to overcrowding, poor ventilation, high prisoner turnover through repeated transfer, late case detection and inadequate treatment of infectious cases, coexisting pathology, particularly HIV and intravenous drug use, poor nutritional status, physical/emotional stresses (2) and the fact that a disproportionate number of prisoners are derived from population groups already athigh risk of TB infection and disease (3) (e.g. those addicted to alcohol or illicit drugs, thehomeless, the mentally ill, former prisoners), who often do not have access to adequate treatment in civilian life (2). This combination of factors makes implementation of TB-control measures in correctional and detention facilities particularly difficult (4).
In 2005, Kenya was ranked tenth out of the twenty two high TB burdened countries in the world, based on estimated number of all forms of incident TB case (5). The total number of TB cases reported in 2005 was ninefold compared to that reported in 1990. HIV epidemic, poor socioeconomic status, over crowded slums in the peri-urban areas coupled with poor nutrition and limited access to health services have been identified as contributing factors to the increasing TB burden (6). It is thus fundamental to establish the factors associated with high TB rates in our prisons in order to implement effectiveand cost-effectivecontrol programmes. Effective MTB infection control in prisons protects the well-being of both the prisoners and the wider community (2). Very few studies have been done in Africa to investigate the risk factors for TB (7), with those associated with active PTB disease among prisoners in Kenya not clearly defined. We carried out this study with the objective of establishing the modifiable factors associated with active PTB disease among prisoners at the Nakuru GK prison, in Kenya; in order to make recommendations for improved TB control. 


\section{MATERIALS AND METHODS}

Study site: The Nakuru G.K prison is one of the 93 penal institutions in Kenya. It is located about $5 \mathrm{~km}$ from the central business area of Nakuru town and was constructed to hold 800 prisoners. The male and female wing is separated and served by different health clinics. During the three and a half month study period it had a daily mean of 1,716 male and 172 female prisoners respectively.

Study design: A retrospective case control study matched by age and sex was conducted at the Nakuru G.K prison between 28th August and 12th December 2007.

Case and control definition: A case was defined as "any adult prisoner (pre-trial or sentenced prisoner aged $>16$ years) who had at least two initial sputum specimens being Acid Fast Bacilli-positive (AFB+) on direct smear microscopy and hence recruited to PTB WHO DOTS Programme". Controls were prisoners with no chronic cough and not on PTB treatment six months prior to the study. Prisoner who self-reported being diagnosed of active PTB disease before incarceration i.e. community acquired PTB were excluded from the study.

Enrollment and sampling procedures: The cases were enrolled by review of the TB register at the prison health clinic then physically identified and a faceto-face interview conducted using a questionnaire. From the daily register of prisoners, a simple random sampling method (without replacement) was used to select participants meeting the control definition. Each enrolled PTB case was allocated two controls matched by sex and five-year age interval. The case together with its two matched controls, were assigned a similar unique identifying number which was then used during analyses.

Sample size determination: A minimum sample size of 138 was determined using the Fleiss formula (8), based on the assumptions that the proportion of active PTB patients and controls exposed to host/environmental factors under study was 56\% and 30\% respectively, with the case to control ratio at 1:2, power at $80 \%$ and 95\% confidence interval.

Data collection tools and methods: A pre-tested semistructured questionnaire was administered to all enrolled study subjects, to collect data on possible host/environmental factors associated with active PTB disease. Study subjects were checked for a typical Bacille Calmette - Guerin (BCG) scar on the upper outer part of the left forearm. Weight (in kilograms) and height (in metres) measurements were taken at the time of enrollment. They were used to compute
Body Mass Index (BMI) by dividing weight with height squared (weight/height ${ }^{2}$ ). The BMI cutoff points considered were underweight (below 18.5); normal weight (18.5 to 24.9 ); overweight (25 to 29.9 ); obese (above 30) (9).

Data managementand analysis: Data were coded during collection. Epi Info version 3.4.3 statistical software was used for data entry and analysis. Descriptive analysis based on frequency distribution of the selected socio-demographic characteristics was done. Matched analysis was performed for the factors associated with active PTB disease, with measure of association being Adjusted (Mantel Hansel) Odds Ratio (OR). McNemars chi-square test was used for categorical variables at $95 \%$ confidences interval (CI) with alpha level of significance at 0.05 . Conditional logistic regression was applied to calculateOR for theexposure variables that were statistically significant during matched analysis, while controlling simultaneously for multiple "potential" confounders. A stepwise backward elimination procedure was conducted to obtain a reduced model. To identify complex interaction, a pair of biologically sensible variables was entered in a conditional logistic model with the unique number used as the matching variable. An alpha level of 0.05 was used to determine the statistical significance of the interactions between pairs of biological sensible factors and active PTB disease.

Ethical issues: Clearance for the study was sought and obtained from the Jomo Kenyatta University of Agriculture and Technology Board of Postgraduate Studies, Permanent Secretary, Ministry of Science and Technology and the Commissioner of Prison Service of Kenya, before commencement of the study. Informed written consent was sought and obtained from the study subjects before administration of questionnaire.

\section{RESULTS}

One hundred and forty four inmates (48 cases and 96 controls) were recruited for this study, with 135 $(94 \%)$ being male. Seventy six of the study subjects reported having attained primary school education while $93(65 \%)$ reported having been self employed prior to incarceration. The ages of the study subjects ranged from 19 to 70 years (median age $=31$ years) . Eighty nine $(62 \%)$ of the enrolled inmates had been incarcerated for a period of one year or less. Approximately 14 (10\%) of the study subjects were found to be underweight while approximately $14 \%$ were found to be overweight.

Overall $96(67 \%)$ of the study subjects admitted knowing their HIV status of which $36(38 \%)$ were PTB cases while $60(62 \%)$ were in the control group. The commonest symptoms reported by cases was night 
sweats $36(75 \%)$ followed by chest pains $32(67 \%)$ (Figure 1). The median duration of anti-TB medication was 66 days (range 1- 150 days).

During matched analysis the significant factors associated with active PTB disease were: self reported $\mathrm{HIV}+$ status $(\mathrm{OR}=9.4,95 \% \mathrm{Cl}=3.2-27.09)$, history of prison transfer $(\mathrm{OR}=3.0,95 \% \mathrm{CI}=1.32-5.40)$, history of a sexually transmitted infection (STI) $(\mathrm{OR}=3.0$, 95\% CI =1.43-6.28), sharing towels and clothes with other inmates while in incarceration $(\mathrm{OR}=2.5,95 \% \mathrm{CI}$ $=1.22-5.13)$, contact with PTB case $(\mathrm{OR}=9.0,95 \% \mathrm{CI}$ $=2.90-29.46)$, alcohol consumption history $(\mathrm{OR}=4.5$, $95 \% \mathrm{CI}=1.98-10.21)$, smoking history $(\mathrm{OR}=3.0,95 \% \mathrm{CI}$ $=1.42-5.59$ ) and unemployment prior to incarceration $(\mathrm{OR}=6.0,95 \% \mathrm{CI}=2.31-5.60)$. The presence of BCG scar was the only significant protective factor $(\mathrm{OR}=$ $0.2,95 \% \mathrm{CI}=0.09-0.43)$ (Table 1$)$.

\section{Figure 1}

Distribution of the clinical presentation of active pulmonary tuberculosis prisoners at Nakuru GK prison in Kenya

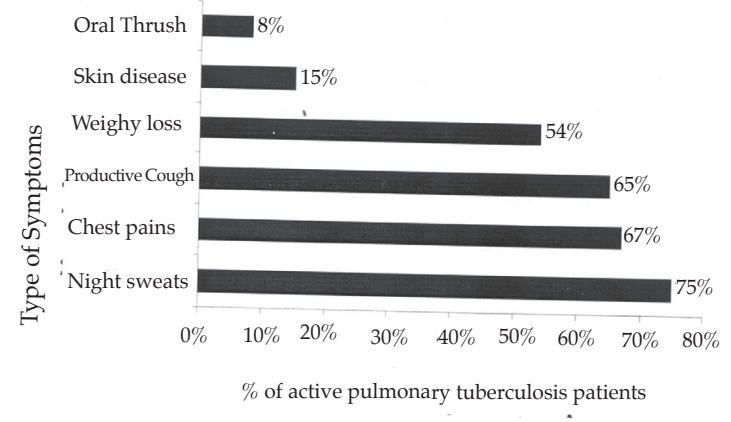

Table 1

Results of factors associated with active PTB infection at Nakuru GK prison during matched and multivariate analysis

\begin{tabular}{|c|c|c|c|c|c|c|c|c|c|}
\hline \multirow[t]{3}{*}{ Exposure } & \multicolumn{6}{|c|}{ Matched analysis } & \multicolumn{3}{|c|}{ Multivariate analysis } \\
\hline & \multicolumn{2}{|c|}{ Case } & \multicolumn{2}{|c|}{ Control } & \multicolumn{2}{|l|}{ Adjusted } & \multirow[b]{2}{*}{ OR } & \multirow[b]{2}{*}{$95 \% \mathrm{CI}$} & \multirow[b]{2}{*}{ P-value } \\
\hline & No & $(\%)$ & No. & $(\%)$ & $\mathrm{OR}(\mathrm{MH})$ & $95 \% \mathrm{CI}$ & & & \\
\hline Self reported HIV + status & 27 & 56 & 12 & 13 & 9.40 & $3.2-27.09$ & 10.75 & $2.42-47.77$ & 0.0018 \\
\hline Presence of BCG scar & 17 & 35 & 76 & 79 & 0.19 & $0.09-0.43$ & 0.17 & $0.05-0.60$ & 0.0059 \\
\hline Unemployment & 22 & 46 & 14 & 15 & 6.00 & $2.31-5.60$ & 8.98 & $1.84-43.97$ & 0.0067 \\
\hline Contact with PTB case & 42 & 88 & 51 & 53 & 9.25 & $2.90-29.46$ & 6.68 & $1.17-38.23$ & 0.0329 \\
\hline \multicolumn{10}{|l|}{ Sharing linen } \\
\hline (clothes/towel) & 21 & 44 & 21 & 22 & 2.50 & $1.22-5.13$ & 4.32 & $1.08-17.29$ & 0.0386 \\
\hline Prison transfer ${ }^{\dagger}$ & 29 & 60 & 33 & 34 & 2.60 & $1.32-5.40$ & & ${ }^{* *} \mathrm{NS}$ & \\
\hline History of $\mathrm{STI}^{+}$ & 25 & 52 & 24 & 25 & 3.00 & $1.43-6.28$ & & ${ }^{* *} \mathrm{NS}$ & \\
\hline Alcohol consumption ${ }^{+}$ & 34 & 71 & 33 & 34 & 4.50 & $1.98-10.21$ & & ${ }^{* *} \mathrm{NS}$ & \\
\hline History of smoking ${ }^{+}$ & 28 & 58 & 27 & 28 & 2.81 & $1.42-5.59$ & & ${ }^{* *} \mathrm{NS}$ & \\
\hline Lack of formal education* & 9 & 19 & 10 & 10 & 2.00 & $0.74-5.37$ & & ${ }^{* *} \mathrm{NS}$ & \\
\hline Low BMI $<18.5^{*}$ & 4 & 8 & 7 & 7 & 1.14 & $0.33-3.92$ & & ${ }^{* *} \mathrm{NS}$ & \\
\hline Having diabetes* & 3 & 6 & 2 & 2 & 3.00 & $0.42-21.30$ & & **NS & \\
\hline Prison stay $>3$ months* & 30 & 63 & 67 & 70 & 0.67 & $0.29-1.15$ & & ${ }^{* *} \mathrm{NS}$ & \\
\hline Prison stay $>6$ months* & 26 & 54 & 55 & 57 & 0.86 & $0.41-1.83$ & & ${ }^{* *} \mathrm{NS}$ & \\
\hline Prison stay> 12 months * & 17 & 35 & 38 & 55 & 0.83 & $0.40-1.73$ & & ${ }^{* *} \mathrm{NS}$ & \\
\hline
\end{tabular}

${ }^{+}$Factors associated with active PTB infection during matched analysis $(\mathrm{p}<0.05)$ that dropped out from the multivariate analysis model.

* Factors not statistically significant during matched analysis ( $\mathrm{p}>0.05)$ and hence not entered into the multivariate analysis model

${ }^{* *} \mathrm{NS}=$ Not Significant 
The model building procedure involved entering these nine variables with a $p$-value of $\leq 0.05$ during the matched analysis in the conditional logistic regression model. The "Best Final Model" had five variables independently associated with active PTB. Self reported HIV + status was found to be the strongest risk factor independently associated with active PTB disease while presence of BCG scar was the only independent protective factor. Otherindependent risk factors were; unemployment prior to incarceration, contact with $\mathrm{PTB}$ case during incarceration period and sharing towel/ clothes withotherinmates (Table1). No statistically significant complex interaction terms were identified as modifying the association between pairs of exposure variables and active PTB disease (Table 2).

Table 2

Results for the complex interaction terms analysis on factors associated with active PTB infection at Nakuru GK prison in Kenya, 2007

\begin{tabular}{lccc}
\hline Complex interaction term & Odds ratio & $95 \% \mathrm{CI}$ & P-value \\
\hline $\begin{array}{l}\text { Alcohol consumption and } \\
\text { smoking }\end{array}$ & 0.37 & $0.07-1.90$ & 0.232 \\
$\begin{array}{l}\text { Contact with PTB case and } \\
\text { sharing linen }\end{array}$ & 1.26 & $0.15-10.75$ & 0.834 \\
HIV+ status and STI & 5.11 & $0.47-55.60$ & 0.181 \\
Lack of formal education and & 1.49 & $0.16-13.56$ & 0.726 \\
$\begin{array}{l}\text { unemployment } \\
\text { Diabetes and low BMI }\end{array}$ & 223452.81 & $0.00>1.0 \mathrm{E} 12$ & 0.968 \\
$\begin{array}{l}\text { HIV+ status and low BMI } \\
\text { Duration of incarceration }\end{array}$ & 0.19 & $0.01-6.17$ & 0.348 \\
$>1$ year and prison transfer & 0.59 & $0.12-2.89$ & 0.515 \\
$\begin{array}{l}\text { Duration of incarceration } \\
>6 \text { Months and prison transfer }\end{array}$ & 0.53 & $0.12-2.39$ & 0.408 \\
$\begin{array}{l}\text { Duration of incarceration } \\
>3 \text { month and prison transfer }\end{array}$ & 0.60 & $0.12-2.93$ & 0.531 \\
\hline
\end{tabular}

\section{DISCUSSION}

The findings from this study indicate that TB and HIV epidemics are closely intertwined in Nakuru GK prison settings. Self - reported HIV+ status was the strongest risk factor associated with active PTB disease though the HIV status could not be ascertained through review of medical records because they were poorly maintained and incomplete. These results are comparable to those documented elsewhere where the estimated risk of clinical disease in HIV-infected persons was between 6 to 26 times higher than in nonHIV infected persons (10). The association between TB and sexual behaviour has rarely been studied, except in the context of HIV infection. Nevertheless in a study in the United States inmates who reported a history of TB also reported higher sexual risk factors than those without such a history, although confounding by HIV infection could not be entirely ruled out (11). Typically, any sexual behaviour is disallowed by prison rules. However it may take many forms, from the request for sex (consensual sex) to forced sodomy. For some inmates, sex is a survival strategy (12). Many prisoners usually come from populations lacking access to reproductive and sexual health services. Prevention, regular screening and treatment of STIs among prisoners would decrease risk of HIV / AIDS and by extension lead to reduction of TB incidence.

Bacille Calmette - Guerin (BCG) vaccination is a part of the WHOrecommended routine immunisation programme for children in Kenya and hence the presence of a typical BCG vaccination scar on the outer upper part of the left forearm was taken as evidence of previous BCG vaccination (4). This study demonstrated that presence of BCG scar was protectively associated with active PTB among adults imprisoned at Nakuru GK prison contrary to other studies carried out in Africa (13). The role of BCG vaccine booster dose in adults, need to be further investigated.

In this study, lack of formal education and/or unemployment prior to incarceration, were taken as proxies for low social economic status (SES). Our statistical significant finding on unemployment concurs with a study in Russia(14) and reiterates that $\mathrm{TB}$ is a disease of the poor and prisoners at Nakuru GK prison are deprive from society of low SES. 
Contact with a person suffering from PTB while under incarceration was independently associated with active PTB disease. This finding concurs with those from a clinic based study conducted in Gambia (15).This suggests lack of isolation of patients with active PTB disease leading to transmission of infection to other inmates either before diagnosis is made or during the early treatment period when one is still infectious.

The fact that sharing of linen was significantly associated with active PTB indicates the occurrence of personal unhygienic conditions in Nakuru GK prison. These findings show similarities to those observed at St. Petersburg remand prison in Russia (16).

Forty three per cent of the study subjects reported being transferred within and outside the Nakuru GK prison, a factor that was only significant during matched but not multivariate analysis. Studies conducted inPakistan's correctional facilities reported an association between history of prison transfer and latent PTB infection among prisoners (4).

The statistical significance of cigarette smoking found in this study is consistent with that reported in a community-based case-control study in West Africa (17). However, this exposure was not found to be an independent risk factor after controlling for multiple potential confounders, which had notbeen addressed in the above previous studies. An effective antismoking campaign boosted by the implementation of the recently enacted "Tobacco Control Act 2007 in Kenya, could have a positive outcome on reduction of TB incidence in Nakuru GK prison.

Alcohol consumption was significantly associated with active PTB disease among prisoners during bivariate but not multivariate analysis. These results are contrary to those reported from India (18) which found alcohol consumption to be an independent predictor of active PTB disease. The alcohol consumption finding in our study could have been underestimated due to security reasons prohibiting strict privacy to this sensitive question.

Lack of formal education, being diabetic and low BMIscore were notsignificantly associated with active PTB disease in this study. Eliciting the correct response for level of education (being a sensitive question), during the study period was affected by responsebias as it was not possible to conduct the questionnaire interviews in strict privacy due to security reasons. This could have affected any significant association expected from this variable in our study. The small sample size among the diabetic prisoners $(4 \%)$ could have affected our results for this exposure. Lack of a significant association of the low BMI value could be related to supplementary diet offered to the PTB patients at Nakuru GK prison.
In this study, $45 \%$ of prisoners had been in prison for less than 200 days. This suggests that prison terms at the Nakuru GK prison are rather short. This could have led to underestimation of the true effect of this exposure factor to the active PTB cases observed. Incarceration duration of more than six months was found to be a risk factor for active TB among prisoners in Botswana, in a one-time survey in a prison system without regular screening at entry (19) and in Cameroon a prison stay of less than 12 months, and a history of previous incarceration were positively associated with PTB (20). Our study focused on incident PTB cases after imprisonment. Prisoner who self-reported being diagnosed of active PTB disease before incarceration were excluded from this study in order to minimise the bias associated with community acquired PTB. The association between the length of incarceration and active PTB was not statistically significant during analysis done at bivariate level and at the complex interaction terms level (Tables 1 and 2).

This study being the first to investigate factors associated with active PTB disease within a prison population in the Kenya's correctional system, will thus form a basis for other studies on factors associated with active PTB disease within other prisons in the Kenya's correctional system. A comprehensive multidisciplinary control and preventive approach involving corroboration between prisoners, health officials and prison authorities, should be adopted in order to reduce the risk associated with PTB control at Nakuru GK prison. This should involve HIV counselling and testing of all PTB patients, screening for TB upon prison entry, TB contact investigation and improving person hygiene of prisoners.

\section{ACKNOWLEDGEMENTS}

The authors thank the following for their various contributionsand support to thisstudy Dr.M.H. Razak, Dr. D. Klauke, Dr. C. Tetteh, Mrs. F. Changwony, and Mr. M. Nahashion. Prisoners and staff at Nakuru Government of Kenya (GK) prison; The Commissioner of Prison Services in Kenya; Staff in the Field Epidemiology and Laboratory Training Programme (FELTP), Kenya, Jomo Kenyatta University of Agriculture and Technology (JKUAT), Institute of Tropical Medicine and Infectious Diseases (ITROMID); Ministry of Public Health and Sanitation, Kenya and finally the Centre for Disease Control and Prevention (CDC), Kenya, that provided the funds for this study, through the FELTP, Kenya. Conflict of interest: None. 


\section{REFERENCES}

1. World Health Organisation. Tuberculosis in prisons. <http: / / www.who.int / tb / challenges / prisons / story_1/en/>: Date last updated: Jan. 2005.

2. World Health Organisation. Tuberculosis control in prisons. A Manual for Programme Managers. WHO/CDS/TB/2000.281. Geneva, World Health Organization 2000.

3. Slavuckij, A., Sizaire, V., Lobera, L., Matthys, F. and Kimerling, M.E. Decentralization of the DOTS programme within a Russian penitentiary system. How to ensure the continuity of tuberculosis treatment in pre-trial detention centres. Eur. J. Pub. Health. 2002; 12: 94- 98.

4. Hamid, H., Saeed, A. and Debra, N. Prevalence of and risk factors associated with mycobacterium tuberculosis infection in prisoners, North West Frontier Province, Pakistan. Int. J. Epidemiol. 2003; 32: 794-799.

5. WHO (World Health Organization). Global tuberculosis control - surveillance, planning and financing, WHO/HTM/TB/2007.376), Geneva/New York/Paris, http: / / www.who.int/tuberculosis/ publications/global report/en/index,html.

6. $\mathrm{MOH}$ (Ministry of Health). TB management guidelines: What the health care worker needs to know. National Leprosy and Tuberculosis Control Programme (NLTP) of the Ministry of Health. 2005.

7. Lienhardt, C. From exposure to disease: the role of environmental factors in susceptibility to and development of tuberculosis. Epidemiol. Rev. 2001; 23: 288- 301.

8. Fleiss, J.L. Statistical Methods for Rates and Proportions, 2nd Edition, John Wiley \& Sons, Inc: New York, 1981.

9. CDC. Centers for Disease Control and Prevention. BMI-Body Mass Index for adults, < http: / / www.cdc. gov/healthyweight/assessing/bmi/index.html> Accessed on 25th June, 2007.

10. Lienhardt, C. and Rodriques, L.C. The impact of HIV infection on tuberculosis; tuberculosis risks revisited. Int. J. Tuberc. Lung. Dis. 1997; 1: 196-204.
11. Stephens, T.T., Braithwaite, R., Cozza, S., Robillard A. and Arriola, K.J. History of prior TB infection and HIV / AIDS risk behaviors among a sample of male inmates in the USA. Int. J. STD AIDS. 2003; 14: 514-518.

12. Reginald, A. W. Sexuality and corrections. An administrator's perspective; Sexuality \& Culture. 2003; 7:11-15.

13. Karonga Prevention Trial Group. Randomised controlled trial of single BCG, repeated BCG, or combined BCG and killed mycobacterium leprae vaccine for prevention of leprosy and tuberculosis in Malawi. Lancet. 1996; 348: 17-24.

14. Richard, C., McKee, M., Rifat, A., et al. Risk factors for pulmonary tuberculosis in Russia case-control study. Brit. Med. J. 2006; 332: 85-87.

15. Philip, C. H., Jackson-Sillah, D., Simon, O., et al. Risk factors for pulmonary tuberculosis: a clinic-based case control study in The Gambia. Bio. Med. Central Public Health. 2006; 6: 156.

16. Lobacheva, T., Asikainen, T. and Giesecke, J. Risk factors for developing tuberculosis in remand prisons in St. Petersburg, Russia - a case-control study. Eur. J. Epidemiol. 2007; 22: 121-127.

17. Lienhardt, C., Fielding, K., Sillah, J.S., et al. Investigation of the risk factors for tuberculosis: a case-control study in three countries in West Africa. Int. J. Epidemiol. 2005; 34: 914-923.

18. Kolappan, C., Gopi, P.G., Subramani, R. and Narayanan, P.R. Selected biological and behavioral risk factors associated with pulmonary tuberculosis Int. J. Tuberc. Lung. Dis. 2007; 11: 999-1003.

19. Centers for Disease Control and Prevention (CDC). Rapid assessment of tuberculosis in a large prison system - Botswana, 2002. MMWR. Morb. Mortal. Wkly. Rep. 2003; 52: RR-12: 250-252.

20. Noeske, J., Kuaban, C., Amougou, G., et al. Pulmonary tuberculosis in the Central Prison of Douala, Cameroon. East Afr. Med. J. 2006; 83: 25-30. 